\title{
Sociolinguistic Competence of Filipino Hotelier and Restaurateur Interns
}

\author{
Ronel M. Sapungan ${ }^{1}$, Romel M. Aceron ${ }^{1}$, Reinier C Castillo ${ }^{1}$, Xhelly Nicole V. Katigbak ${ }^{1} \&$ Dianna M. $^{2}$ \\ Villanueva $^{1}$ \\ ${ }^{1}$ Batangas State University JPLPC-Malvar, Philippines \\ Correspondence: Ronel M. Sapungan, College of Accountancy, Business, Economics, and International \\ Hospitality Management, Batangas State University JPLPC-Malvar, Philippines. Tel: 639-217-490-578
}

Received: December 13, 2018; Accepted: December 17, 2018; Published: December 20, 2018

\begin{abstract}
Concern over the pressing problem on communication skill is evident among the Filipino Hotel and Restaurant Management (HRM) students and graduates as revealed in observations and several studies. The condition posed challenges to both teachers and students as it was commonly observed by the language teachers and the researchers themselves. Hence, the importance of this qualitative research, which, by using a semi-structured interview, was conducted with the primary objective of determining the level of sociolinguistic competence of HRM interns relative to register and dialect, cultural reference, and metaphorical language. Twenty-five participants were purposively chosen based on the following considerations: the availability and flexibility of schedule; ability to communicate in English; had undergone on-the-job training for the last two semesters. The researchers considered the respondents' work experience, work assignment and type of establishment as baseline data of the study. In determining the participants' sociolinguistic competence, the researchers used the semi-constructed interview questions which were validated by language experts. The frequency and percentage were used to determine the respondents' profile and standard rubrics for their responses. Cohen's Kappa Interpretation was also used to determine the level of sociolinguistic competence. The study revealed that majority of the respondents worked as a housekeeper, assigned at the back of the house, and worked in the hotels. It also disclosed that trainees were found to be in Beginning Level with regard to their level of sociolinguistic competence. Interpersonal communication intervention may be proposed to Hotel and Restaurant Management department for implementation to improve students' sociolinguistic competence.
\end{abstract}

Keywords: sociolinguistic competence, register and dialect, cultural reference, metaphorical language, hotelier and restaurateur interns

\section{Introduction}

Communication is what connects people as human beings, and it is also one of the most important concern in life. People can express their feelings and thoughts by the help of communication; it is also a way of sharing beliefs and culture to one another. In today's life good communication skills is vital all over the world and having it can lead someone to success in any career.

According to Flores (2016), the human society cannot function without communication. Society exists and grows with every communication activity between and among persons within that society. The people are social beings who interact with one another all the time. That's why it has been said that the people cannot not communicate. They are engaged in conversation, dialogues, interviews, committee meeting, public speaking and organizational or cultural interchanges. Therefore, people are all communicators. The challenge is whether they can communicate well or not.

The most important part in order to be a good communicator is having a sociolinguistic competence. This is the ability to communicate well or to have good communication skills. According to Wiley-Blackwell (2011), sociolinguistic competence is our unconscious knowledge of languages and the organizing principles of a language. What actually produced as utterances is linguistic performance. However, in the case of Filipino hotelier and restaurateur interns, they cannot communicate with the guests confidently due to low mastery of the English language, lack of practice in speaking the English with correct grammar, least transactional skills, inability to connect their ideas in the context, low confidence and poor communication techniques and style. 
Sociolinguistic competence has an important role in the conduct of an internship program. Internship is an experiential education that encompasses an array of potential experiences. It includes service-learning internships, academic service-learning, community service-learning, cooperative education programs, and applied practicum. According to Sapungan et al. (2018), an internship is skills-training for professional growth and for mastering both methodology and discipline. Thus, students are required to undergo this training to obtain the essential knowledge and develop their skills and become competent member of global workforce.

The researchers believe that the Hospitality On-The-Job (OJT) trainees improve their way of communication during internship. This internship program helps them to be sociolinguistic competent. As interns, Hospitality trainees have to understand three parts sociolinguistic competence, the register and dialect, cultural references and figure of speech. The register and dialect refers to the grammatical choices as made of the speaker depending on the situational context. The cultural reference approaches to the language-culture relationship since culture spread across languages and likewise languages spread across cultures. And lastly, the figure of speech, this is the speaker different way of pronouncing a word such as with alliteration to give further meaning or different sound and the use of comparison to reveal the true meaning of the words.

Communication is the heart of any organization. Lack of communication competence cannot help improve the company. Employees who speak with respect, listen, handle conflict, and are heard in meetings are greatly appreciated by employers. Therefore, communication can make things easier especially to the workers or OJT trainees who are working in hospitality industry because they tend to deal with different kinds of people or hotel guests.

The study of Dawson (2011) revealed that one out of four foodservice employees speaks a foreign language at home. Furthermore, 37 percent of those employees speak limited English. Given this, hospitality managers must find ways to effectively communicate with their employees. Therefore, there are hospitality employees who cannot communicate well and that is a problem because in their field of work they tend to deal with different kinds of people or guests.

The researchers conducted this study because hospitality students will deal with different kinds of people. Communication is vital on their field that's why it is also believed that this will benefit the hospitality students who have problems in communication. Aceron (2015a) stressed that in social context language is an element of social activities that can be grounded in the details of actual events. Furthermore, this study is conducted for the benefit of OJT who need to be good communicators before going to the field. Upon assessing the sociolinguistic competence of the OJT trainees an interpersonal communication program may be proposed by the researchers to help OJT trainees improve their communication in their field of work.

As the researchers tried to determine the sociolinguistic competence of OJT trainees, this study was deemed significant as the result could possibly be used as basis for proposing an interpersonal communication intervention. The researchers believed that this study could help the Language Instructors to improve their student's way of communicating. It can be used to know how to communicate well. Because this study wanted to propose an interpersonal communication program, it will help the employers and managers to hire and train the employee to have an ability to communicate well and to know how to deal with different people. The researchers also focused on the sociolinguistic competence of the hospitality OJT. This study can also help the Hospitality Students so while they undergo to their OJT they know how to deal with different people by having good communication skills. Lastly, this study can help the researchers and future researchers to hook information about the research study of sociolinguistic competence. It will provide some knowledge about the level of sociolinguistic competence of OJT that may help them formulate their next research.

\subsection{Objectives of the Study}

The main objective of the study was to determine the sociolinguistic competence of Bachelor of Science in Hotel and Restaurant Management On-the-Job Trainees (OJT). Specifically, it aimed to achieve the following objectives: to determine the profile of respondents in terms of work experience, type of assigned work, and type of establishment; to describe and analyze the sociolinguistics competence of On-the-Job trainees in terms of register and dialect, cultural references, and metaphorical language; and to design an Interpersonal Communication Program for Hoteliers and Restaurateur based on the findings.

\subsection{Theoretical Framework}

This research is anchored on Canale and Swain's Communicative Competence Theory (1980). This theory provides the contents and boundaries of four areas of competence, or systems of knowledge, that are to be minimally included in a theory of communicative competence: grammatical competence, sociolinguistic 
competence, and strategic competence. Grammatical competence is concerned with the rules of sentence grammar and sentence grammar semantics. Sociolinguistic competence includes sociocultural rules for determining the social meaning and appropriateness of a single sentence or utterance; it also includes discourse rules for determining the cohesion and coherence of groups of utterances. Strategic competence is composed of verbal and nonverbal communicative strategies that are used to compensate for breakdowns in communication due to performance factors or to insufficient grammatical or sociolinguistic competence. It is suggested that the value of such a theoretical framework for second language learning is that it provides a clear initial statement, or construct, of communicative competence. Such a statement is helpful not only for the purposes of second language teaching but also for those of second language testing.

Canale and Swain (1980) took up this notion of communicative competence and distinguished four aspects of communicative competence: Grammatical/linguistic competence, which includes knowledge of the lexicon, syntax and semantics (mastery of language codes); Sociolinguistic competence is concerned with the appropriateness of communication depending on the context including the participants and the rules for interaction; Strategic competence, a set of strategies devised for effective communication and put into use when communication breaks down (grammatical and sociolinguistic strategies); and Discourse competence is concerned with the cohesion and coherence of utterances/sentences.

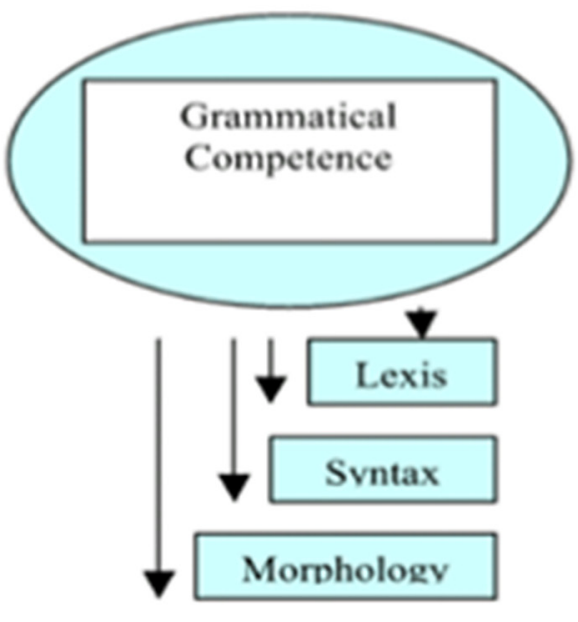

\section{Phonologv}

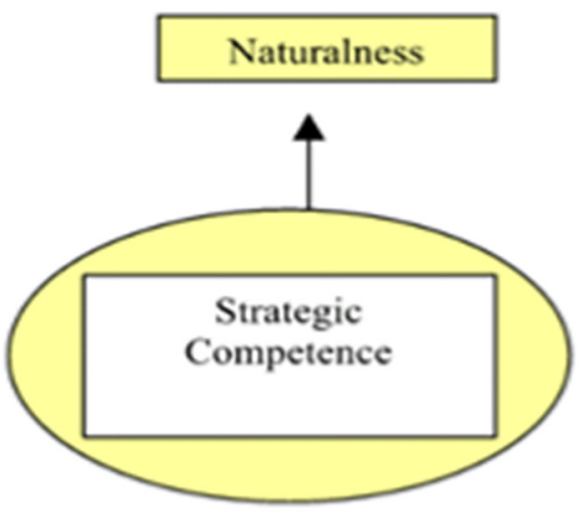

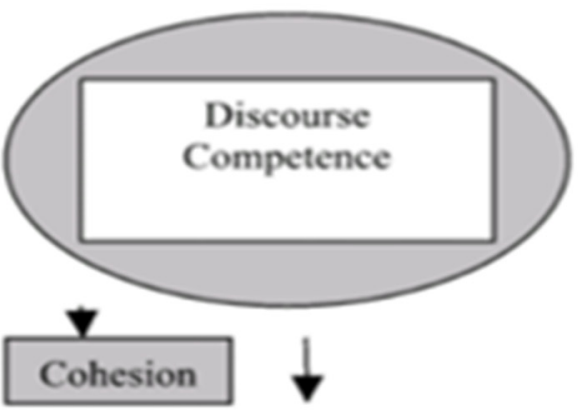

Rhetorical Organization
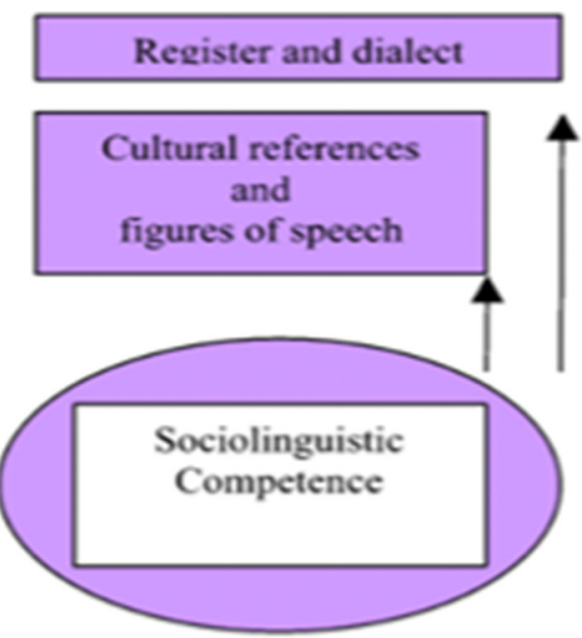

Figure 1. Model of Communicative Competence by Canale and Swain

\subsection{Operational Framework}

The main aim of the research was to determine the level of sociolinguistic competence of hotelier and restaurateur interns. The operational conceptual framework presented below was the basis of how the researchers were able to obtain pertinent data that were analyzed and interpreted. The findings of the study were considered in designing the proposed interpersonal communication program. 


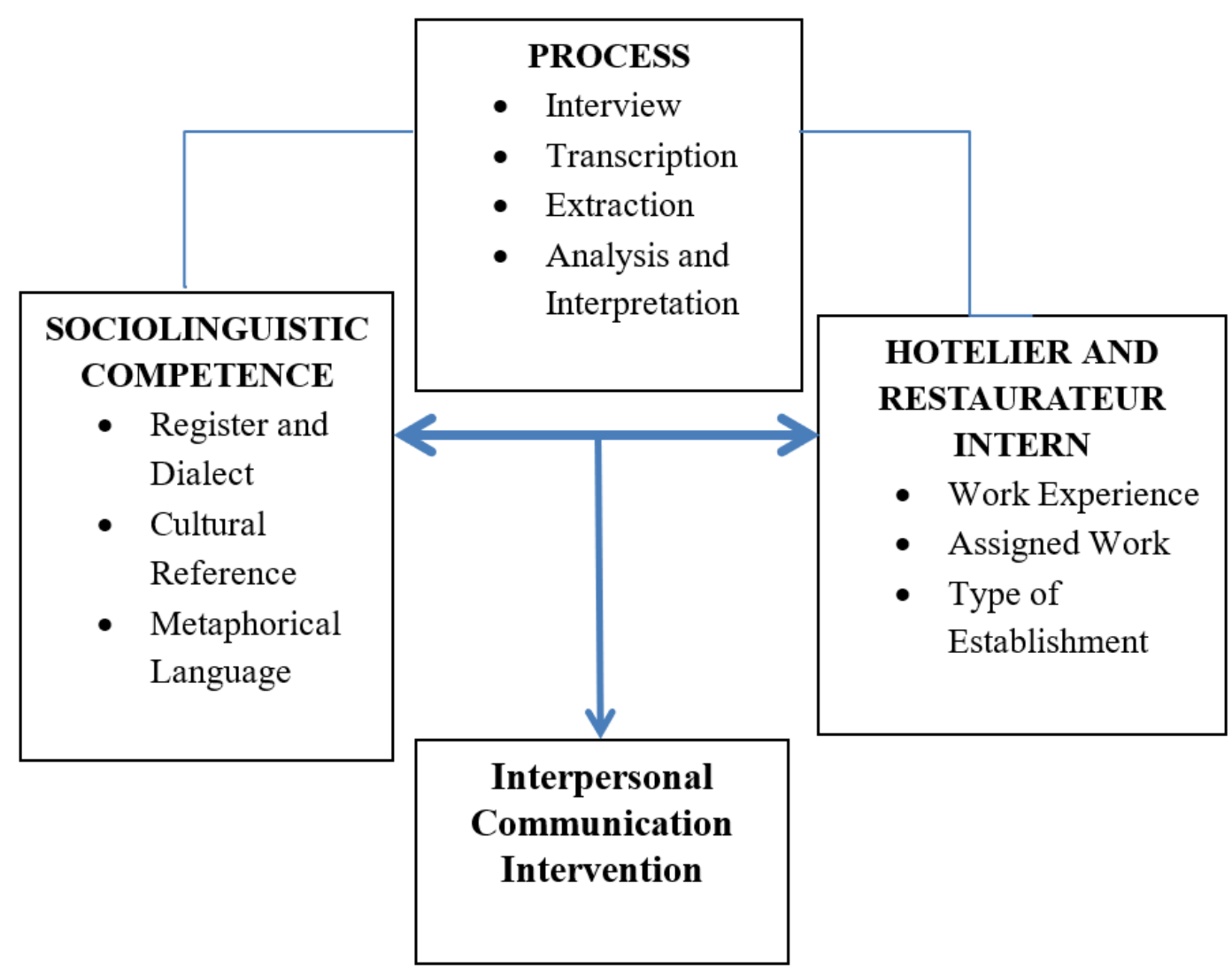

Figure 2. Operational Framework for Interpersonal Communication Intervention

The box contains the profile of the respondents such as work experience, type of assigned work, and type of establishment they are working. It also includes the level of sociolinguistic competence in terms of register and dialect, cultural reference and metaphorical language. The Process box contains the interview, transcription, extraction and data analysis and interpretation. The expected output of the study is the interpersonal communication intervention to improve the sociolinguistic competence of hotelier and restaurateur intern.

\subsection{Assumption}

The study assumed that hotelier and restaurateur interns have a good facility and command of the language, and have sociolinguistic competence.

\section{Methods}

\subsection{Research Design}

The study determined the level of sociolinguistic competence of Hospitality students who has undergone in an Onthe-Job-Training (OJT). Qualitative research is the type for this study. Creswell (1998) defines qualitative study as a "qualitative inquiry that employs different philosophical assumptions; strategies of inquiry; and methods of data collection, analysis and interpretation"

The researchers considered interview as a chief data-gathering tool. Weiss (1994) explains, "Interviewing gives us a window on the past. Based on his definition, interviewing can tell settings that would otherwise be familiar with the interviewer such as distant societies, best organizations, and the private lives the interviewees." Fettermen (1989) supports Weiss contention saying interviews can produce more ideas and information because interviewees can express their ideas in speaking. This holds right when the people speak the language comfortable for them. Hence, the researchers used English when he conducted the interviews. Using English made the participants relaxed and were confident to talk generously about their views and perceptions on motivations and challenges.

\subsection{Respondents of the Study}

The study aimed to determine the profile of respondents in terms of work experience, type of assigned work, and type of establishment. It focused on the level of sociolinguistic competence of hospitality students who had 
undergone OJT; the researchers targeted 25 on-the-job trainees from different establishments. They came from different establishments like hotel and restaurants. The researchers considered the hospitality students who undertook OJT on June to July 2017. This study aimed to determine which aforementioned factors that affected the level of sociolinguistic competence of the OJT.

\subsection{Sampling Design}

The researchers used a purposive sample, a non-probability sample, to select the respondents/participants based on their characteristics of a population and the objective of the study. Purposive sampling is also known as judgmental, selective, or subjective sampling. This type of sampling is very useful in a situation that needs to reach a targeted sample quickly, and where sampling for proportionality is not the main concern.

\subsection{Measurement and Instrumentation}

The researchers read books, researches, and other printed materials which dealt on the topic. From this, the researchers constructed the survey questionnaire based from the specific questions formulated.

Researchers utilized rubrics, which composed of two parts. The first part consists the profile of the respondents such as work experience, type of assigned work, and type of establishment they're working. The second part consists of the factors affecting the level of sociolinguistic competence of hospitality on-the-job trainees, such as; register and dialect, cultural reference and metaphorical language.

The researchers made use of four designated verbal interpretation to interpret the level of sociolinguistic competence of the OJT trainees. Mastering as the highest point which means that the respondents are sociolinguistic competent and can communicate well down to beginning as the lowest point which means that the respondents needs to improve his/her communication skills. The researchers also prepare interview questions for interview.

Before conducting the interview, the rubric and interview questions were given to the adviser, panelists, faculty and other experts first for their comments and approval. After the approval, the interviews were conducted. The researchers used the audio recorder as the chief data gathering instrument followed by the transcription and coding of data obtained. The transcribed and coded data had been categorized and extracted for analysis and interpretation.

\subsection{Research Procedure}

The researchers gathered information from different sources in order to come up with the topic. They sought some advice from research experts and browsed the internet. They continued searching related literature and studies substantiate the study.

Table 1. Rubrics for Assessing Sociolinguistic Competence

\begin{tabular}{|c|c|c|c|c|}
\hline Criteria & $\begin{array}{l}\text { Mastering } \\
4 \\
\end{array}$ & $\begin{array}{l}\text { Achieving } \\
3\end{array}$ & $\begin{array}{l}\text { Developing } \\
2\end{array}$ & $\begin{array}{l}\text { Beginning } \\
1\end{array}$ \\
\hline $\begin{array}{l}\text { Register } \\
\text { - } \quad \text { Structure of words } \\
\text { - } \quad \text { Configuration of } \\
\text { semantic resources }\end{array}$ & $\begin{array}{l}\text { Has the ability to construct } \\
\text { good structure } \\
\text { appropriately. }\end{array}$ & $\begin{array}{l}\text { Has the ability to } \\
\text { construct good } \\
\text { structure appropriately } \\
\text { but have rare } \\
\text { mistakes. }\end{array}$ & $\begin{array}{l}\text { Can make quite good } \\
\text { structure of words } \\
\text { appropriately but } \\
\text { sometimes there are } \\
\text { mistakes. }\end{array}$ & $\begin{array}{l}\text { Have bad structures } \\
\text { of words and have } \\
\text { often mistakes }\end{array}$ \\
\hline $\begin{array}{l}\text { Dialect } \\
-\quad \text { Process of words } \\
-\quad \text { Variety of language }\end{array}$ & $\begin{array}{l}\text { Has the ability to process } \\
\text { the words appropriately } \\
\text { according to the topic }\end{array}$ & $\begin{array}{l}\text { Has the ability to } \\
\text { process the words } \\
\text { appropriately } \\
\text { according to the topic } \\
\text { but have rare } \\
\text { mistakes. }\end{array}$ & $\begin{array}{l}\text { Can process the words } \\
\text { but sometimes there } \\
\text { are mistakes and not } \\
\text { appropriate to the topic }\end{array}$ & $\begin{array}{l}\text { Have bad way of } \\
\text { processing words } \\
\text { and have often } \\
\text { mistakes }\end{array}$ \\
\hline $\begin{array}{l}\text { Cultural reference } \\
\text { - } \quad \text { Origin } \\
\text { - } \quad \text { Language-culture } \\
\text { - } \quad \text { Vernacular language }\end{array}$ & $\begin{array}{l}\text { Has the ability to } \\
\text { communicate effectively } \\
\text { while using the language- } \\
\text { culture of the country and } \\
\text { deliver the meaning } \\
\text { successfully. }\end{array}$ & $\begin{array}{l}\text { Has the ability to } \\
\text { communicate } \\
\text { effectively while using } \\
\text { the language-culture } \\
\text { of the country but } \\
\text { have rare mistakes. }\end{array}$ & $\begin{array}{l}\text { Can communicate } \\
\text { while using the } \\
\text { language culture and } \\
\text { improvingly delivers } \\
\text { the meaning but } \\
\text { sometimes there are } \\
\text { mistakes. }\end{array}$ & $\begin{array}{l}\text { Can't deliver the } \\
\text { meaning of the } \\
\text { words while using } \\
\text { language culture } \\
\text { and have often } \\
\text { mistakes in using it. }\end{array}$ \\
\hline Metaphorical Language & Know how to use figure of & Know how to use & Can use figure of & Having trouble in \\
\hline
\end{tabular}




\begin{tabular}{|c|c|c|c|c|}
\hline $\begin{array}{l}-\quad \text { Non-literal meaning } \\
\text { - } \quad \text { Describe something } \\
\text { through comparison }\end{array}$ & $\begin{array}{l}\text { speech effectively and can } \\
\text { easily deliver the proper } \\
\text { meaning. }\end{array}$ & $\begin{array}{l}\text { figure of speech } \\
\text { effectively and } \\
\text { appropriately but have } \\
\text { rare mistakes. }\end{array}$ & $\begin{array}{l}\text { speech and } \\
\text { improvingly delivers } \\
\text { the proper meaning of } \\
\text { words but sometimes } \\
\text { there are mistakes. }\end{array}$ & $\begin{array}{l}\text { using figure of } \\
\text { speech and can't } \\
\text { deliver the proper } \\
\text { meaning. Have } \\
\text { often mistakes in } \\
\text { using it. }\end{array}$ \\
\hline
\end{tabular}

The researchers used a self-constructed type of rubric and questions. The researchers sought the expertise of language gurus and research experts to validate the rubrics and the questions used for the interviews. After the validation and agreement of experts, the researchers communicated with university authorities to allow them to conduct the interviews among their respondents.

The researchers personally interviewed the respondents using the rubric to assess their responses. Thirty (30) minutes to one (1) hour was allotted to allow the interviewees to speak comfortably and freely about the questions. With twelve questions for the semi-structured interview, the researchers used lead-in questions as preliminaries of the interview. One important lead-in question was "Tell me about yourself as an HRM student?" The two other leading questions were "Where and when did you have your on-the-job training?" and "What challenges/problems had you encountered during the training? To support the actual interviews, the researchers used an audio recording to record the details of the conversations as well as served as materials for the experts' evaluation using the given criteria.

After the interviews, the researchers tallied the responses and grouped them according to their theme and profile. The researchers transcribed and extracted the conversation in order to give accurate data. The grouped data interpreted by the researchers and took note of the findings, and formulated conclusions and recommendations.

The result of the statistical computation guided the researchers in the interpretation and analysis of the data. The frequency and percentage were used to measure the profile of the respondents in terms of work experience, type of assigned work, and type of establishment. The Cohen's Kappa Interpretation was used to test the reliability of questions and the agreement between the researchers' assessment and the experts'.

\section{Results}

The data gathered through different research instruments are presented and discussed thoroughly in this section. The inputs include the profile of the respondents and the level of their sociolinguistic competence. The presentation of discussion follows the logical sequence of the specific problems posted in the objectives of the study. The succeeding graphs present the profile of the respondents in terms of work experience, type of assigned work and type of establishment.

\subsection{Work Experience}

Work experience is the task of respondents in their past work or job. Figure 3 presents the distribution of respondents in terms of work experience.

\section{Respondents' Profile: Work Experience}

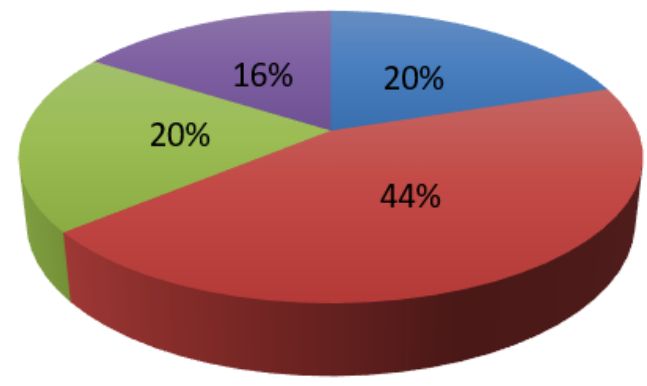

- Waiter/waitress

Front liner
- Housekeeper

- Food and beverage attendant

Figure 3. Distribution of the Respondents in terms of Work Experience 
As presented in Figure 3, majority of the respondents had experienced being housekeeper with a frequency of 11 or percentage of 44 while waiter/waitress got a frequency of 5 and percentage of 20 percent. The respondents who had experience being a front liner got the frequency of five and percentage of 20 percent while the food and beverage attendant got the lowest frequency of 4 and percentage of 16 percent. This means that those who experienced being a housekeeper perform a vital role in the hospitality industry, and this is the department which requires more manpower than the other departments.

This presents that most of the respondents prefer to work as a housekeeper because this field is in demand in hospitality industry owning the fact that this is the biggest department in this field and it provides lot of jobs and opportunity. This finding got support from Singh and Ad (2017) stating that like any other department housekeeping offers an individual to make a successful career and achieve different heights in the management up to the level of General Manager. As the job opportunities increase in hotels, and housekeeping department being the largest employer alone department wise as stated in a report by National Skill Development Corporation 2012, it is definitely a great time for employees who wish to advance their career or choose housekeeping as their career choice. Therefore, most of the respondents prefer to work at the housekeeping department because of the big opportunities and huge employment of this field.

The waiter/ waitress and front liner got the same frequency of 5 or 20 percent while the food and beverage department got the lowest frequency of 4 and percentage of 16 percent. The reason is because these departments require less staffs than the departments in the back of the house. It indicates that housekeepers are given the more opportunity as observed.

\subsection{Type of Assigned Work}

Assigned work is the department or field of work of someone who is working in hospitality industry. Figure 4 presents the distribution of respondents in terms of assigned work using frequency and percentage.

\section{Respondents' Profile: Assigned Work}

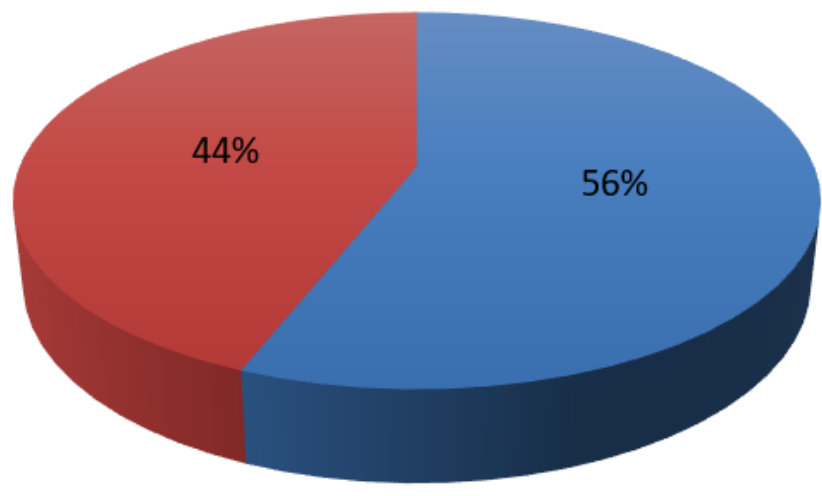

\section{Back of the house Front of the house}

Figure 4. Distribution of the Respondents in terms of Assigned work

As shown in the figure, majority of the respondents worked at the back of the house with a frequency of 14 or 56 percent while the respondents who worked at the front of the house got the frequency of 11 or 44 percent. This means that majority of the respondents prefer to work at the back of the house because they are more engaged in cooking or preparing foods for the customers aside from the fact that there are lots of opportunity in this department.

It can be viewed that the respondents chose back of the house because it refers to those operation of the hotels that deals with housekeeping and food and beverage department which is in need of more man power and provides lot of opportunity in different country all around the world. This is similar to the research of Hospitality Crossing (2017) revealed that although most top management and executive positions lie in the front of the house, the best sources for experience and the most opportunities for advancement lay in the back of the house. The back of the house refers to those operations of the hotel that deal with housekeeping, food, and engineering, and which are seldom observed by guests. While restaurant operations involve direct contact with guests, they are so integral a part of food operations that they are described in this section. In this case the reason why back of the house is the preferred area of the respondents is because it is a great source of experience and opportunities. 


\subsection{Type of Establishment}

Type of establishment is the type of hospitality establishment that the respondents worked for. Figure 5 shows the distribution of respondents in terms of type of establishment using frequency and percentage.

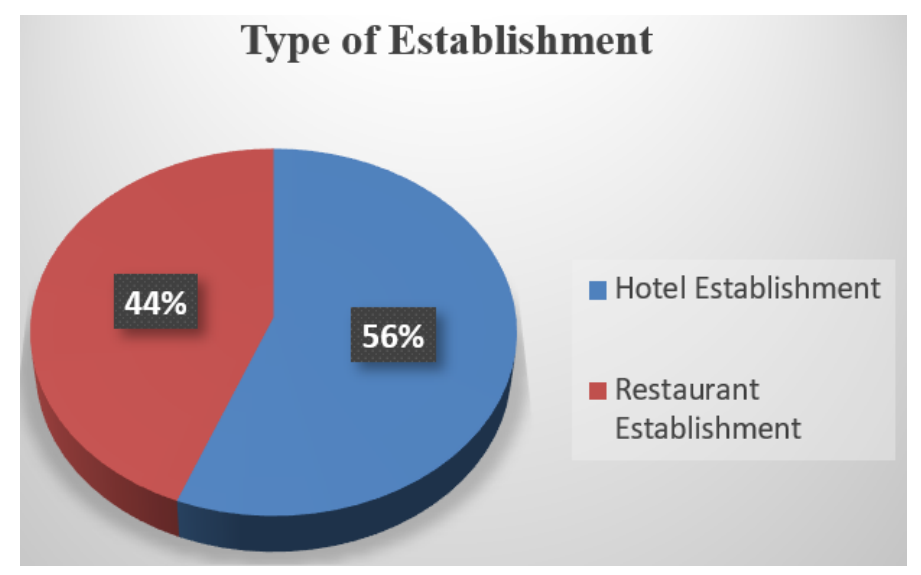

Figure 5. Distribution of respondents in terms of Type of Establishment

As shown in the figure above majority of the respondents worked at the hotel establishment with the frequency of 14 and percentage of 56 percent while the respondents who worked at the restaurant establishment got the frequency of 11 and percentage of 44 percent. This means that majority of the respondents worked in the hotel because hotel establishment is the biggest part of the hospitality industry and hotel establishment needs more manpower rather than the restaurant establishment.

It suggests that the respondents prefer to work in hotel establishments because hotel has different department like front office, housekeeping and food and beverage department. In addition, this is one of the rising industries that can provide lots of job opportunities.

This is similar to the study of EHL (2018) stating that the massive, steady growth in the hospitality industry is in hotel it creates opportunities for managerial and executive employment, new businesses, and innovation. Hospitality is a generic term that includes all activity sectors where customer satisfaction is the key, and the primary goal is to ensure the best customer experience possible. It means that hotel is massive in hospitality industry that's why most of the respondents chosen to work in the hotel.

\subsection{Sociolinguistics Competence of On-the-Job Trainees}

The sociolinguistic competence of the OJT trainees includes the register and dialect, cultural reference, and metaphorical language.

The following extracts show how the respondents answered the questions using their ability to construct structure of words and how they processed it according to register and dialect. Register is a way of speaking or writing including vocabulary, syntax and pronunciation (or spelling) chosen by individuals to express themselves depending on the circumstances they speak, while dialect is a variety of English which is associated with a particular region and/or social class. To state the obvious, speakers from different geographical regions speak English rather differently

\section{Extract 1}

Interviewer: What is your work experience in the hospitality industry? Respondent 1: Well its quite different when your just studying and when you are in the hospitality industry itself, it is quite difficult because ah you already have the contact the direct contact between the customers and it quite difficult for me because the job is so pres... I have so much pressure and so yun nga I am pressure specially when dealing with the customers because they have ah different attitudes but then it is quite amazing that I practice my I ah..yung maaga ako napapractice yung nasa hospitality industry because it's give me so much experience yung mga ano to. Yung what What Im going to expect in the hospitality as soon ah but I can say that I am happy and its very I love this work 
even though it is difficult but I love working in the hospitality industry.

Respondent 2: My work experience is being a laundry attendant and a

housekeeper.

Respondent 3: I experience being a housekeeper.

Respondent 4: My experience in hospitality industry is being a

housekeeper and a chef.

Respondent 5: My work experience in the hospitality industry

$a h m$ ojt is being a housekeeping.

Respondent 6: I have experience in Yellow Cab Pizza Food

Company as front liner as cashier staff.

Respondent 7: Ah good morning I worked in Jollibee Corporation.

It can be analyzed and interpreted in Extract 1 that Respondent 1 has the mastery of her answer, as she has a good structure of words. She has the ability to construct good structure of words and process it appropriately. When an individual has an ability of the rules of language, he or she may efficiently and effectively process the ideas for good sense and its meaning. It can also be noted that the sociolinguistic competence of an individual may be influenced by their emotional impart, cognitive processes and motivating power (Aceron, 2015b).

According to Young (2012) register is the form that language takes in different circumstances, and "code switching" is the ability to go from one register to another guided by context. Register is an essential social skill that provides flexibility and demonstrates competence in speech and appropriate social norms. Even for experienced interpreters, register is difficult to master, as it relies not only on the language itself, but also on social customs, culture, and even personal preferences. As a relationship progresses between individuals, the register they use may evolve to be more informal. Unlike words and grammatical structures, register follows its own set of rules, and it's hard to hit the mark on it exactly. In most cases, close enough is usually sufficient.

It can also be interpreted in the extract that respondent 1 have mastery in answering the question, while the other six respondents are in developing level. It is noticeable that only respondent 1 elaborated her answer and constructed words effectively other than the rest of the respondents who answered the question directly but committed errors in structure of words as evident in the extract " My work experience in the hospitality industry ahm ojt is being a housekeeping".

As to how she processed her words, respondent 5 was not able to construct the word well instead of housekeeper she verbalized housekeeping.

\section{Extract 2}

Interviewer: okay so how do you describe the guest you encountered? Respondent 8: Moody, imfetient (Impatient), hindi marunong makapag hintay

Respondent 9: The guests are very pleasant.

Respondent 10: Marami sa mga guest na naka salamuha ko ay masungit yun pala'y mabait.

Respondent 11: Designation $k o$ is front of the house so madami akong na eencounter na mga guest, may mga foreigner tyaka yung mga local.

Respondent 12: Hindi pako naka kaencounter ng guest kasi sa loob ng kitchen ako naassign.

Respondent 13: Yun naka encounter akong foreigner yun mabait naman and nagbigay ng tip

Respondent 14: Iba iba kasi merong $m g$ a foreigner kasi nga diba chinese resto hindi lang pinoy may masungit, merong madaming complaints pero bilang guest kailangan ibigay mo yun.

As can be seen and analyzed in Extract 2, respondents eleven and fourteen have the achieving level in answering the question because they have the ability to construct good structure of words and process it appropriately but have rare mistakes. When an individual has the ability to process and deliver the words he or she can be effective in communicating.

According to Benjamin (2013), an individual may choose his dialect as a speech register for informal occasions, and a standardized language of a larger social unit on formal occasions. A speech register is a way of speaking or writing including vocabulary, syntax and pronunciation (or spelling) chosen by individuals to express themselves depending on the circumstances they speak: high register (formal occasions like parliamentary speech, official 
documents, celebrations), low register (informal occasions, conversations among family or friends' group). There are also many in-between registers and specialized occasions like religious services, sport events, and so on.

It can be interpreted in extract 2 the comparison of the respondents. The respondents 8, 10,12 and 13 got the level of developing as evident on the extracts:

Moody, imfetient (Impatience), hindi marunong makapag hintay Marami sa mga guest na naka salamuha ko ay masungit yun pala'y mabait. Hindi pako naka kaencounter ng guest kasi sa loob ng kitchen ako naassign. Yun naka encounter akong foreigner yun mabait naman and nagbigay ng tip

While it can be seen that the respondents 11 and 14 that is in the level of achieving are both working in the restaurant as waiter/waitress as evident in the extract: Designation ko is front of the house so madami akong na eencounter na mga guest, may mga foreigner tyaka yung mga local. Iba iba kasi merong mga foreigner kasi nga diba chinese resto hindi lang pinoy may masungit, merong madaming complaints pero bilang guest kailangan ibigay mo yun.

They deal with the guest most of the time that's why they are better in communicating and constructing the structure of words rather than those respondents who are working in the back of the house.

\section{Extract 3}

Interviewer: How do you handle and manage guest complaints?

Respondent 15: Ah minamanage ko naman yung mga guest na nag cocomplaints syempre in a good way tsaka pinapakiusapan na yung mga hindi kayang maibigay agad ng isang establishment or ng pinagtatrabahuhan

Respondent 16: Siguro pag may guest na nagcomplaint itatanong ko ang problema kung san nagkamali oh ano yung pinoproblema nya syempre pag ganun dapat mababa boses mo para magfeel comfortable sya at hindi sya magalit tapos alamin ko yung problema para matulungan ko sya kung ano yung kinocomplaint nya.

Respondent 17: I'm solving it and its too difficult to handle on dealing with the guest I let the manager to handle.

Respondent 18: Ahm dun na man sa mga guest complaints ahm ano ahm nakikipagusap kami ng maayos ahm atsaka in a good way yung pag sagot namin or yung pagrespond namin sa kanila para maganda rin yung ahm feedback nila dun sa hotel na pinagtatrabahuhan ko. Respondent 19:Una tinatanong muna kung anong nangyari tas evaluate tapos itatanong sa mga superior kung anong pwedeng gawin towards dun sa complaints tapos pag okay nababalikan ang guest tapos ayon. Respondent 20: So I can handle ah guest complaint as we have the (SOP) or the standard operating procedure so I just follow it if there are any concern or any anything I can do or if I cannot do I just go it through my manager to the front office manager.

Respondent 21: Ahm by doing my ano with all my knowledge and sincerity to solve their complaints and if pag hindi kona kaya then I call my manager to explain that to the guest kung pano gagawin nila regarding dun sa complaint.

As can be interpreted and analyzed in extract 3 all of the respondents are in achieving level except respondent 17 that is in developing level because his construction of words is unclear and the process is incorrect. When an individual cannot construct a good structure of words it may lead to wrong meaning and understanding of she or he wants to say.

According to McWhorter (2016), a language is written in addition to being spoken, while a dialect is just spoken. But in the scientific sense, the world is buzzing with a cacophony of qualitatively equal 'dialects,' often shading into one another like colors (and often mixing, too), all demonstrating how magnificently complicated human speech can be. If either the terms 'language' or 'dialect' have any objective use, the best anyone can do is to say that there is no such thing as a 'language':

It can be seen that majority of the respondents answered the question with good structure of words and they process it appropriately for example: 
Respondent 20: So I can handle ah guest complaint as we have the (SOP) or the standard operating procedure so I just follow it if there are any concern or any anything I can do or if I cannot do I just go it through my manager to the front office manager.

Respondent 19:Una tinatanong muna kung anong nangyari tas evaluate tapos itatanong sa mga superior kung anong pwedeng gawin towards dun sa complaints tapos pag okay nababalikan ang guest tapos ayon.

They delivered the words successfully and the meaning was quite clear even though there was shifting of words from Tagalog to English. It can also be interpreted that most of the respondents were comfortable in Tagalog.

\section{Extract 4}

Interviewer: What types of hospitality establishments did you work for?

Respondent 22: ahm I want to work in restaurant establishment pa din

Respondent 23: ahm what type of hospi hospitality establishment I

will work for? In the dining area

Respondent 24: I worked for the restaurant.

Respondent 25: In hotel.

Respondent 1: Hospitality establishment I prefer to work, well

for now I'd like to experience what is the feeling working in the

hotel industry. Because I haven't been in the hotel working in the

hotel industry so I want to experience new things that is related

into my course so that it will give me another and new experience

as well

Respondent 2: Hotel establishment.

Respondent 3: Sa hotel.

It can be interpreted that only respondent 1 got the level of mastery in answering the question while the others is still on the level of developing they can make good structure of words but there's a problem in the process. When an individual can make good structure of words it is easily for them to deliver what they are trying to say.

Young (2012) claimed that all experienced the occasional verbal slip-up, whether one is nervous or the words just cannotcome out right. In casual speech between friends, a faux pas is usually laughed off and moved on from as quickly as it appeared. However, in business meetings and professional speeches, they are a little harder to overlook. A major source of faux pas encountered in interpretation work is the tricky element of language known as register. Spoken language takes on different levels of formality depending on the social situation and the relationships between those involved. Register is the form that language takes in different circumstances, and "code switching" is the ability to go from one register to another guided by context. Register is an essential social skill that provides flexibility and demonstrates competence in speech and appropriate social norms. Even for experienced interpreters, register is difficult to master, as it relies not only on the language itself, but also on social customs, culture, and even personal preferences. As a relationship progresses between individuals, the register they use may evolve to be more informal. Unlike words and grammatical structures, register follows its own set of rules, and it is hard to hit the mark on it exactly. In most cases, close enough is usually sufficient.

It can be analyzed the comparison of respondents on the way they answered the question. Respondent 1 answered the question with good word structure and processed it appropriately. She also elaborated her answer in order to understand what she meant as evident in the extract: "Hospitality establishment I prefer to work, well for now I would like to experience what is the feeling working in the hotel industry. Because I have not been in the hotel working in the hotel industry so I want to experience new things that is related into my course so that it will give me another and new experience as well." The rest of the respondents answered direct to the point and deliver their message without elaboration."

Aceron (2015c) emphasized that a good facility of the English language is indeed significant which makes the individuals express and understand the flow of ideas. He called that the knowledge in grammar may develop one's proficiency or competence in both oral and written communication.

The following extracts show the answers of the respondents as they use their language-culture or cultural reference. Culture reference is the idea that relates to a specific culture; things that only someone can understand a specific culture. Language is associated to one's culture because it can help identify the practices and orientations through the words and expressions they use in communication.

\section{Extract 5}

Interviewer: what departments are you assigned to work? 
Respondent 1: okay well actually I am working in the banquet and catering service my work there is I am assigned in the service, ah waitress yun I am a service provider especially ah I always assigned in the presidential tables yon so I give them the ano

Respondent 2: Housekeeping and laundry department.

Respondent 3: I am assigned in housekeeping and laundry department.

Respondent 4: Housekeeping at kitchen.

Respondent 5: Housekeeping

Respondent 6: In dinning.

Respondent 7: I assigned in kitchen department

It can be interpreted that respondent 1 has the level of achieving in answering this question because she had the ability to communicate effectively while using the language-culture of the country but had rare mistakes. A cultural reference is when people refer to something that relates to the language-culture like the shifting of words from English to their vernacular language.

According to Risager (2008) that the link between language and culture when a communicative event takes place; by communicative event she means any social event, which also refers to a cultural event, so the best term is sociocultural event in which language culture is used in a local integration with discursive and other cultural flows. She analyses the relationship between language and culture from three different perspectives: sociological, psychological and linguistic.

It can also analyzed the comparison of the respondents since respondent one is the only one who's achieving level and the rest is developing because most of the respondents answer the question direct to the point and their cultural reference is not present on their answer for example: Respondent 2: Housekeeping and laundry department. Respondent 3: I am assigned in housekeeping and laundry department. Respondent 4: Housekeeping at kitchen. Respondent 5: Housekeeping. Respondent 6: In dinning. Respondent 7: I assigned in kitchen department

While Respondent 1 answered the question better than the other respondents as evident in the extract: Respondent 1: okay well actually I am working in the banquet and catering service my work there is I am assigned in the service, ah waitress yun I am a service provider especially ah I always assigned in the presidential tables yon so I give them the ano. She elaborated her answer and there's a shifting of words from English to Tagalog.

\section{Extract 6}

Interviewer: What department do you prefer to work? Back of the house or front of the house? Why?

Respondent 8: Front of the house. I encountered any guest Respondent 9: I preferred to work at the back of the house. Respondent 10: Back of the house. Dahil mas mahihirapan ako humarap sa mga tao.

Respondent 11: back of the house. Gusto ko kasi yung ano madaming nakakausap, syempre sa front of the house madami kang makakasalamuhang ibat ibang tao.

Respondent 12: back of the house. Kasi ayokong makipag interact sa mga guests and customers.

Respondent 13: I prefer to work at the front of the house Kasi gusto kong mabuild yung self-confidence ko, gusto ko sanang makita yung mga naseservan kong guest naka ngiti nag papasalamat yung ganun,

Respondent 14: Mas prefer ako sa front of the house. Kase kaya ko namang mag ano mag handle ng guest tsaka mas naii nashoshow ko yung aking ano skills.

As shown in Extract 6, respondent thirteen is achieving in answering the question. It can see the transition of words from English to Tagalog on how she answered the question as evident in the extract she said: I prefer to work at the front of the house Kasi gusto kong mabuild yung self-confidence ko, gusto ko sanang makita yung mga naseservan kong guest naka ngiti nag papasalamat yung ganun. The language-culture can be seen by using vernacular language or different dialects in her country. 
The study Kramsch (2009) in the first perspective, language and culture can be separable, since it is possible for a language to express or create, as would say, different realities or cultures. In the psychological perspective these two are inseparable, since an individual carries all the linguistic and cultural experience within oneself. The third perspective is valid only in the practice of linguistics where language is analyzed outside of its cultural context.

The Extract 6 can also present the comparison of respondents by their way of answering the question. As it can be seen, there is a difference on the way they shift the words from one language to another. Cultural references are also not only specific to the country one is in. In cities, towns, or communities there may be language-culture that are specific to the people of that area.

\section{Extract 7}

Interviewer: Is your work assignment tending you to deal with guest or customers?

Respondent 15: Yes, kasi as front desk nakakausap ko yung mga

guest

Respondent 16: Oo

Respondent 17: Yes.

Respondent 18: Yes

Respondent 19: Oo, kasi ano sa housekeeping pag may magmamakeup

room kailangan tinatanong din ang guest tsaka dun sa iyon.

Respondent 20: Yes, ahm tending I would just go through I will

entertain I will Through encountered guest as I was said I am in the

front office it's the first thing to do when I am in transitioning the

reservation of rooms I just encountered so many people.

Respondent 21: Yes, ano because we have sa ano sa front-liner kasi

we have specific task we have specific na tinatarget so meron

kaming mga ano yung inaabot na assignment yung nakaano samin

naka assigned samin.

As presented in Extract 7 respondent twenty one is achieving her answer while the rest is considered as developing though respondent twenty have a great answer her language-culture is not present on it because she uses full English as evident in the extract: Respondent 20: Yes, ahm tending I would just go through I will entertain I will Through encountered guest as I was said I am in the front office it's the first thing to do when I am in transitioning the reservation of rooms I just encountered so many people. The language-culture is hard to interpret especially when an individual is not speaking on his or her vernacular language.

Kramsch also stated that cultural reference refers to the relationship of language 'creating' socially shared realities or cultures - even if they are only temporary -, "language is used not just as a tool for the exchange of information, but as a symbolic system with the power to create and shape symbolic realities, such as values, perceptions, identities through discourse".

The comparison of respondents can also be interpreted in Extract 7 as mentioned respondent 20 answered in English while respondent 21 who got then level of achieving answered the question with combination of English and Tagalog. Therefore respondent 21 shown her language-culture and it differed from the others because she had a good structure of words.

\section{Extract 8}

Interviewer: The next question is what hospitality establishment do you prefer to work?

Respondents 22: in kitchen dept.. kitchen

Respondent 23: ahmm I prefer to work in the restaurant as what I said earlier I'm prefer to work at the back of the house Respondent 24: Ahm I prefer to work at the hotel because I want to experience being a housekeeper and a laundry attendant at the same time I want to experience being in the front office. Respondent 25: In hotel

Respondent 1: Hospitality establishment I prefer to work, well for now I'd like to experience what is the feeling working in the hotel industry. Because I haven't been in the hotel working in the hotel industry so I want to experience new things that is 
related into my course so that it will give me another and new experience as well.

Respondent 2: Hotel establishment

Respondent 3: Restaurant.

It can be interpreted and analyzed in Extract 8 that all of the respondents got the level of developing in terms of answering this question because all of them answer in English and did not use their vernacular language even though respondent one came up with a good answer the language-culture is still missing as evident in the extract: "Hospitality establishment I prefer to work, well for now I'd like to experience what is the feeling working in the hotel industry. Because I haven't been in the hotel working in the hotel industry so I want to experience new things that is related into my course so that it will give me another and new experience as well."

When an individual can use language-culture effectively it would be easily for him or her to communicate with different people because he can adjust his structure of words depends on who is he talking to.

As Kramsch stressed that language and culture can be separable, since it is possible for a language to express or create, as would say, different realities or cultures. In the psychological perspective these two are inseparable, since an individual carries all the linguistic and cultural experience within oneself. The third perspective is valid only in the practice of linguistics where language is analyzed outside of its cultural context.

The extracts below show how the respondents used their metaphoric language as the ability to use opposite of literal language, which uses words directly according to proper meaning. Metaphorical language in other words refers to the effective use of metaphors to create a vivid pictures or image of the idea being conveyed by the speaker or writers. It is a common language using common terms to express clear comparison of two different things.

\section{Extract 9}

Interviewer: okay so if there is one thing you can compare your work what is it?

Respondent 1: well something that I can compare to my work, for now as a student's my work is... I think it's my life it is hard you know working in the industry while studying here at school especially when you have so much paper works but then I cannot give up my work because it gives me so much hap yung happiness that I cannot see here because you know I love working in the hospitality industry even if it's so difficult because yun nga I practice my the skills and all the things that I have learned here in school mas maganda kasi nga mas maaga ko napapractice yun before going and entering the real world of hospitality industry itself and even if nakakapagod sobra sobrang hirap na anong oras ka umuuwi everytime everyday ano yung happiness na naidudulot non kahit nakakapagod especially when you saw your customers your guest are smiling at you and thankful especially whenever I had I ano they give me tips so much tips I am happy because not despite the money I am know that in my self within me I gave them what they deserve so that binalik nila yun sakin so kahit nakakapagod I am happy and I think it's really my life and I continue looking forward to work in the hospitality industry.

Respondent 2: I can compare my work to a clock because I enjoy every seconds of my time while I'm working.

Respondent 3: Maikukumpara ko ito sa isang libro maraming dapat matutunan

Respondent 4: Sa study kasi marami akong natututunan.

Respondent 5: Gold because every time ahm I like a gold cause time is gold.

Respondent 6: I will compare my work as oven, because when you bake something, you need more patience to wait for better result of everything.

Respondent 7: ah I compare in clock becau- because the time is gold. 
It can be analyzed in Extract 9 that everyone can use metaphorical language but it matters on how they use it. As shown in the extract only respondent 1 has mastery in answering the question in terms of how she use figure of speech as well as how she delivered it as evident on the extract: "well something that I can compare to my work, for now as a student's my work is... I think it's my life it is hard you know working in the industry while studying here at school especially when you have so much paper works but then I cannot give up my work because it gives me so much hap yung happiness that I cannot see here because you know I love working in the hospitality industry even if it's so difficult because yun nga I practice my the skills and all the things that I have learned here in school mas maganda kasi nga mas maaga ko napapractice yun before going and entering the real world of hospitality industry itself and even if nakakapagod sobra sobrang hirap na anong oras ka umuuwi everytime everyday ano yung happiness na naidudulot non kahit nakakapagod especially when you saw your customers your guest are smiling at you and thankful especially whenever I had I ano they give me tips so much tips I am happy because not despite the money I am know that in my self within me I gave them what they deserve so that binalik nila yun sakin so kahit nakakapagod I am happy and I think it's really my life and I continue looking forward to work in the hospitality industry." Metaphorical language is the ability of someone to use opposite of literal language, which uses words directly according to proper meaning.

According to Benedek et al. (2013), metaphorical language comprehension involves forming an abstract connection between two concepts in semantic memory. Such a link, or attributive category, is established by extracting and relating similar properties of different concepts in memory. For example, the metaphor music is medicine involves identifying the conceptual category "something that is healing", abstracting the properties of music and medicine that are related, and inhibiting the properties that are unrelated. This model has also been used to conceptualize metaphor production.

The comparison of the respondents can also be interpreted in the Extract 9. Every respondent can use figure of speech and answered the question directly they got the level of developing except from Respondent 1 who really explained her answer and used figure of speech with good word structure, thus, she could be qualified in mastery level.

\author{
Extract 10 \\ Interviewee: Describe your work assignment? \\ Respondent 8: I mix the vanilla soft surf and prepare all all drinks \\ of the guest and I assist all the guest. \\ Respondent 9: Cleaning the room and following the standard \\ of the hotel. \\ Respondent 10: Ang work assignment ko ay maglinis ng room. \\ Respondent 11: My work assignment is I'm a cashier and server \\ so I'll do multi-tasking meron kasing time na mag isa ka lang sa \\ dining area so ikaw lahat ang gagawa ng trabaho na pwedeng \\ gawin ng alam mo yun pwedeng gawin ng tatlo pero nagagawa mo \\ mag isa. \\ Respondent 12: Nag pu-pull out ako ng drinks and nag a-assemble \\ din ako ng mga desserts \\ Respondent 13: Maihalin.. Made-describe ko yung assignment \\ sakin work assignment.. I mean naglilinis ng mga room, bathroom \\ ganun.
}

Respondent 14: Madalas ko lang ginagawa yung pag seserve

tsaka yung complementary food kase bilang sa chinese resto

laging pag nag se.. pag pumasok ang isang guest laging merong

welcome food.

As shown in the Extract 10 all of the respondents got the degree of beginning because they don't manage to use figure of speech although they answered the question. When an individual can't use figure of speech it means that they're having trouble in relating one thing to something that can describe it.

The Handbook of Psycholinguistic (Traxler M. and Gernsbacher M., 2008) stated that figurative language does not constitute a unified class of linguistic materials that are understood by special figurative processes. Nonetheless, the indeterminate nature of many aspects of figurative meaning, a fact that is not properly acknowledged in many psycholinguistic studies, raises important issues about the possible trade-off between minimizing cognitive effort and maximizing cognitive effects during figurative language processing. This trade-off can be empirically studied and form the basis for future psycholinguistic research on figurative language. One of the continuing difficulties 
with the psycholinguistics literature on figurative language understanding is that few scholars ever attempt to define the terms literal and figurative. A traditional assumption in many academic disciplines is that literal meaning is primary and the product of default language comprehension. Thus, in psycholinguistic terms, the human language processor is designed for the analysis of literal meanings. Nonliteral, indirect, and figurative meanings are secondary products, and dependent on some prior analysis of what words and expressions literally mean. This general theory implies that nonliteral meanings should always take more time to interpret than are literal meanings.

It can also be interpreted the comparison of the respondents even if they have the same level there are still difference in the way they answered questions like for example the answer of Respondent 11: My work assignment is I'm a cashier and server so I'll do multi-tasking meron kasing time na mag isa ka lang sa dining area so ikaw lahat ang gagawa ng trabaho na pwedeng gawin ng alam mo yun pwedeng gawin ng tatlo pero nagagawa mo mag isa, she explained her answer well and elaborated it while the answer of Respondent 10 was Ang work assignment ko ay maglinis $n g$ room. It is specific and direct to the point.

\section{Extract 11}

Interviewee: Why do you want to work here?

Respondent 15: Because siguro dahil ano sa hotel kase before yun yung mas napag tuunan ng pansin kasi yun yung trabaho ko before. Respondent 16: Kase parang ano parang yung mga kasamahan mo don mga mababait parang feeling comfortable ka magagawa mo yung trabaho mo ng maayos.

Respondent 17: Since I've done my OJT and I already encountered different situations I know that I could do the same things when I'm ahm already working.

Respondent 18: Ahm dun sa sinabi ko na back of the house ahm gusto ko sa kitchen so mas maganda na siguro na dun ako sa restaurant. Respondent 19: Doon? Ano yun nga katulad ng sinabi ko maraming learning experience atsaka nationalities na din.

Respondent 20: Just simple I want here to work because this is my passion cause I want to serve to the guest I want to serve to the other people I want to improve my self-esteem as of course but I will overcome it .

Respondent 21: Kasi I've been in a restaurant work experience and also my OJT experience was a restaurant also then I want to work naman sa hotel industry

It can be interpreted in Extract 11 that all respondent was at the beginning level in answering the question because the metaphorical language was not present on their answer but there's a difference in the way they answered the question for example Respondent 20:

Just simple I want here to work because this is my passion cause I want to serve to the guest I want to serve to the other people I want to improve my self-esteem as of course but I will overcome it. She answered fluently in English while Respondent fifteen:Because siguro dahil ano sa hotel kase before yun yung mas napag tuunan ng pansin kasi yun yung trabaho ko before.

She answered it with the shifting of English and Tagalog words though she stuttered a little bit it can be seen that she was more comfortable in speaking English rather than using his vernacular language.

According to Perrine (2018), figurative language has been widely examined by linguist in the study of literature in recent years. It is because figurative language has the essence of style and beauty. Figurative language often provides a more effective means of saying what we mean than direct statement. In the specific sense, figurative language may take the form of figures of speech. Figurative language is used in any form of communication, such as in daily conversation, articles in newspaper, advertisements, novels, poems, etc.

\section{Extract 12}

Interviewee: Do you have any feedback on your work before?

Respondent 22: wala naman

Respondent 23: ahmm for me it's very challenging because you are... you are communicating with other people you are exploring new things but it was fun and I like it.

Respondent 24: Ahm yes, I learned about many things being a waiter 
and a greeter I learned how to read the emotion of our guest.

Respondent 25: Yes, because I'm enjoy.

Respondent 1: whenever I I said that ah I'm done working I want to ganyan ganyan they don't say anything bad at ah and its quite amazing when they thank me sabi thank you for working with us ganyan thank you for sharing your skills and hope that we give you such an experience that you'll gonna that you'll gonna use in your studies and in your future work.

Respondent 2: It is a great experience. I have learned many things.

Respondent 3: It is a memorable experience.

As shown in the Extract 12 it can be interpreted that all of the respondents are in the level of beginning they answer the question without using metaphorical language and some of them used wrong structure of words. Having an ability to use figure of speech can lead someone to understand better and use it to relate something to another things.

Perrine added that the effectiveness of figurative language in four main reasons, first, figurative language affords readers imaginative pleasure of literary works. Second, it is a way of bringing additional imagery into verse, making the abstract concrete, making literary works more sensuous. The third, figurative is a way of adding emotional intensity to otherwise merely informative statements and conveying attitudes along with information. And the last, it is a way of saying much in brief compass. She divides figurative language into seven types, namely metaphor, simile, personification, metonymy, paradox, overstatement, understatement, irony and illusion.

Table 2. Percentage of Agreement between the Researchers as to Register

\begin{tabular}{|c|c|c|c|}
\hline \multirow[t]{2}{*}{ Question } & \multicolumn{2}{|c|}{ Researchers } & Difference \\
\hline & $\mathbf{A}$ & $\mathbf{B}$ & \\
\hline 1 & 1 & 1 & 0 \\
\hline 2 & 1 & 1 & 0 \\
\hline Number of Zero's & & & 2 \\
\hline Number of Items & & & 2 \\
\hline Percentage of Agreement & & & $100 \%$ \\
\hline
\end{tabular}

Legend-a-researcher 1, $\boldsymbol{b}$-researcher 2

It can be analyzed in Table 2 the researchers got 100 percent agreement to the questions for dialect because they believed that the questions can be answered with good structure of words. Aside from that the questions can determine their work experience in hospitality industry by answering with good structure of words.

Good structure of can be seen when someone has the ability to communicate grammatically correct and he can easily deliver what he wants to emphasize. The researchers wanted to determine the respondents experience in working at the same time to know their ability to construct words.

According to the article of Menabney (2015) effective speakers use simple but good structure of words to keep their audiences engaged. You can repeat certain phrases in order to create a crescendo, or what's known as a "rhythmic build." This is a skill President Obama uses frequently in his speaking. For example, in the closing of his September address to the United Nations, he said, "They can be made to fear, they can be taught to hate, but they can also respond to hope." A rhythmic build with three simple repetitions is best-four or five is usually overkill.

Table 3. Percentage of Agreement between the Experts as to Register

\begin{tabular}{cccc}
\hline Question & \multicolumn{2}{c}{ Experts } & Difference \\
\cline { 2 - 3 } 1 & $\mathbf{A}$ & $\mathbf{B}$ & \\
2 & 1 & 1 & 0 \\
Number of Zero's & 1 & 0 & 1 \\
$\begin{array}{c}\text { Number of Items } \\
\text { Percentage of Agreement }\end{array}$ & & & \\
\hline
\end{tabular}

Legend- $\boldsymbol{A}$-expert 1, B-expert 2 
As shown in Table 3, the Experts got 50 percent of agreement in the questions for register because it was viewed that the question determined the way they constructed words. Some of the respondent's answers are having good structure of words. The question also determined their work experiences which have an impact in the way they answered the questions.

Register is the knowledge of appropriate behavior, distinct from skill and effectiveness; it is argued that competence should be viewed as a function of knowledge, skill, and motivation. In the proposed approach, competent communication refers to functionally effective interaction appropriate to a given relational context. These impressions of appropriateness and effectiveness are more likely when a person is motivated to communicate, knowledgeable about communication, and skilled in communicating in a particular interpersonal relationship and context (Spitzberg, 2009).

Table 4. Summary of Agreement between the Researchers and the Experts as to Register

\begin{tabular}{|c|c|c|c|c|c|c|c|c|c|}
\hline \multirow[t]{2}{*}{ Criteria } & \multicolumn{2}{|c|}{ Researchers } & \multirow[t]{2}{*}{ Dab } & \multicolumn{2}{|c|}{ Experts } & \multirow[t]{2}{*}{ DAB } & \multicolumn{3}{|c|}{ Qualitative Description } \\
\hline & $\mathbf{A}$ & b & & $\mathbf{A}$ & B & & $\mathbf{R}$ & $\mathbf{E}$ & PA \\
\hline Beginning & 12 & 8 & 4 & 16 & 19 & 3 & Partial & Partial & Partial \\
\hline Developing & 8 & 13 & 5 & 9 & 6 & 3 & Partial & Partial & Partial \\
\hline Achieving & 4 & 3 & 1 & 0 & 0 & 0 & Partial & Partial & Partial \\
\hline Mastery & 1 & 1 & 0 & 0 & 0 & 0 & Perfect & Perfect & Perfect \\
\hline
\end{tabular}

Legend: a- researcher 1, $\boldsymbol{b}$ - researcher 2, $\boldsymbol{A}$ - expert 1, B-expert 2, Dab-difference between researchers 1 and 2, $\boldsymbol{D A B}$ - difference between expert 1 and $2, \boldsymbol{R}$ - qualitative description of expert, $\boldsymbol{E}$ - qualitative description of researchers and $\boldsymbol{P} \boldsymbol{A}$ - percentage of agreement.

As to register, Table 4 reveals that only few are found to have the mastery as indicated to their ability to construct English language well, with minor grammatical errors. Most of the respondents could hardly build a good structure of words because they are having hard time thinking on how they would answer the questions.

The study of Chin (2010) stated that grammar is the sound, structure, and meaning system of language. All languages have grammar, and each language has its own grammar. People who speak the same language are able to communicate because they intuitively know the grammar system of that language - that is, the rules of making meaning. Students who are native speakers of English already know English grammar. They recognize the sounds of English words, the meanings of those words, and the different ways of putting words together to make meaningful sentence.

Table 5. Percentage of Agreement between the Researchers as to Dialect

\begin{tabular}{cccc}
\hline Question & \multicolumn{2}{c}{ Researchers } & Difference \\
\cline { 2 - 3 } & $\mathbf{A}$ & $\mathbf{B}$ & \\
1 & 1 & 1 & 0 \\
2 & 1 & 0 & 1 \\
Number of Zero's & & & 1 \\
Number of Items & & & 2 \\
Percentage of Agreement & & & $50 \%$ \\
\hline
\end{tabular}

Legend-a-researcher 1, $\boldsymbol{b}$-researcher 2

As shown in the table, the researchers got 50 percent agreement to the questions for dialect because one of the researchers did not agree to question number 2 although it can be used to determine how the respondents processed their answer in the right way in order to give accurate answers. The questions can also determine their work experience and what establishment they are working.

The study of Benjamin (2011) stated that language processing is changing in two ways that should make it more relevant to the study of grammatical learning. First, grammatical phenomena are re-entering the psycholinguistic fray, and we have learned a lot in recent years about the real-time deployment of grammatical knowledge. Second, psycholinguistics is reaching more diverse populations, leading to much research on language processing in child and adult learners. 
Table 6. Percentage of Agreement between the Experts as to Dialect

\begin{tabular}{cccc}
\hline Question & \multicolumn{2}{c}{ Experts } & Difference \\
\cline { 2 - 3 } & A & B & \\
2 & 1 & 0 & 1 \\
Number of Zero's & 0 & 0 & 0 \\
Number of Items & & & \\
Percentage of Agreement & & \\
\hline
\end{tabular}

Legend-A-expert 1, B-expert 2

It can be interpreted in Table 6 that the expert got 50 percent of agreement because the most of the respondents answered using their vernacular language as Tagalog and they delivered the meaning right even they used switching of language from English to Tagalog. It is acceptable to switch language as long as the meaning is still there and can easily be understood by the interviewee.

According to Hudson (2014), a dialect is a variety of English which is associated with a particular region and/or social class. To state the obvious, speakers from different geographical regions speak English rather differently: hence we refer to 'Geordie' (Newcastle English), 'New York English' or 'Cornish English.' In addition to geographical variation, the social background of a speaker will also influence the variety of English that person speaks: two children may grow up in the same Yorkshire village, but if one is born into a wealthy family and attends an expensive private school, while the other is born into a less well-off family and attends the local state school, the two are likely to end up speaking rather different varieties of English. It is this combination of regional and social variation that I refer to collectively as 'dialect'.

Table 7. Summary of Agreement between the Researchers and the Experts as to Dialect

\begin{tabular}{|c|c|c|c|c|c|c|c|c|c|}
\hline \multirow[t]{2}{*}{ Criteria } & \multicolumn{2}{|c|}{ Researchers } & \multirow[t]{2}{*}{ Dab } & \multicolumn{2}{|c|}{ Experts } & \multirow[t]{2}{*}{ DAB } & \multicolumn{3}{|c|}{ Qualitative Description } \\
\hline & $\mathbf{A}$ & b & & $\mathbf{A}$ & $\mathbf{B}$ & & $\mathbf{E}$ & $\mathbf{R}$ & PA \\
\hline Beginning & 12 & 15 & 3 & 20 & 22 & 2 & Partial & Partial & Partial \\
\hline Developing & 8 & 7 & 1 & 5 & 3 & 2 & Partial & Partial & Partial \\
\hline Achieving & 5 & 8 & 3 & 0 & 0 & 0 & Perfect & Partial & Partial \\
\hline Mastery & 0 & 0 & 0 & 0 & 0 & 0 & Perfect & Perfect & Perfect \\
\hline
\end{tabular}

Legend: a- researcher 1, b- researcher 2, A- expert 1, B- expert 2, Dab- difference between researchers 1 and 2, DAB- difference between expert 1 and 2, R- qualitative description of expert, E- qualitative description of researchers and PA- percentage of agreement.

It can be interpreted in table, that most of the respondents are found to be beginning in terms of dialect because of their ability to process the words is inappropriate they could hardly construct their answers well especially in English language. They could answer the questions directly but the process was not present on their answer because most of the respondents spoke in their vernacular language; thus, this may be interpreted that the respondents were not competent in using the English language.

Table 8. Percentage of Agreement between the Researchers as to Cultural Reference

Legend-a-researcher 1, b-researcher 2

\begin{tabular}{cccc}
\hline Question & \multicolumn{2}{c}{ Researchers } & Difference \\
\cline { 2 - 3 } & $\mathbf{A}$ & $\mathbf{B}$ & \\
1 & 1 & 1 & 0 \\
2 & 1 & 1 & 1 \\
3 & 0 & 1 & 0 \\
4 & 1 & 1 & 0 \\
Number of Zero's & & & 3 \\
Number of Items & & & 4 \\
Percentage of Agreement & & & $75 \%$ \\
\hline
\end{tabular}


According to the article of Educause (2018) natural language processing combines the power of artificial intelligence with linguistics to process and analyze language-based data. NLP considers the building blocks of language as data and analyzes these data segments, looking for latent structures and patterns in language. It helps linguists understand aspects of a language and conduct studies comparing one language to another. It informs the technology that drives online translation software and speech-recognition applications. NLP has the potential to contribute to learning analytics and efforts to support student success.

As shown in the Table 8 the researchers got 75 percent of agreement in the questions for cultural reference. The questions can determine their work assignment and it can also be used to interpret their language culture. The researchers did not agree to question 3 because it is answerable by yes or no but apart from that this question would know if the respondents were dealing with the guests or not.

The most essential skill that employers look for is the ability to speak effectively in English. This ability is especially true of sectors, namely the Human Resource Development (HRD), where communication at the internal and external level is an important requirement of the job. Previous studies in Malaysia have found that members of staff often face problems such as speaking fluently and presenting in front of a large audience. This paper reports on an investigation of English Language Oral Communication (ELOC) needs of HRD undergraduates from a public university in the Southern part of Malaysia. The findings identified the specific oral communicative events and skills required by HRD trainees at the workplace (Tawadorus, MI., Antiado, DF., and Castillo, FG , 2012).

Table 9. Percentage of Agreement between the Experts as to Cultural Reference

\begin{tabular}{cccc}
\hline Question & \multicolumn{2}{c}{ Experts } & Difference \\
\cline { 2 - 3 } & A & B & \\
1 & 1 & 1 & 0 \\
2 & 1 & 1 & 0 \\
3 & 1 & 1 & 0 \\
4 & 1 & 1 & 0 \\
Number of Zero's & & & 4 \\
Number of Items & & 4 \\
Percentage of Agreement & & $100 \%$ \\
\hline
\end{tabular}

Legend-A-expert 1, B-expert 2

As shown in Table 9, it can be interpreted that the experts got 50 percent of agreement in the questions for cultural reference the respondents answered the question with their language-culture or using their vernacular language. Majority of them answered in Tagalog and it was found that they were more comfortable in answering the questions using Tagalog language. Another reason may be attributed to the too often use of Filipino language in the classrooms and in many circumstances in the campus. This may also be attributed to the fact that not all instructors are using English in the delivery of class instructions.

Sociolinguistic competence is the exchange and flow of information and ideas from one person to another; it involves a sender transmitting an idea, information, or feeling to a receiver. Effective Sociolinguistic competence occurs only if the receiver understands the exact information or idea that the sender intended to transmit. Many of the problems that occur in an organization are fail to communicate and process of confusion (Jaggers et. al, 2008).

Table 10. Summary of Agreement between the Researchers and the Experts as to Cultural Reference

\begin{tabular}{|c|c|c|c|c|c|c|c|c|c|}
\hline \multirow[t]{2}{*}{ Criteria } & \multicolumn{2}{|c|}{ Researchers } & \multirow[t]{2}{*}{ Dab } & \multicolumn{2}{|c|}{ Experts } & \multirow[t]{2}{*}{ DAB } & \multicolumn{3}{|c|}{ Qualitative Description } \\
\hline & $\mathbf{a}$ & B & & A & B & & $\mathbf{E}$ & $\mathbf{R}$ & PA \\
\hline Beginning & 5 & 7 & 2 & 20 & 23 & 3 & Partial & Partial & Partial \\
\hline Developing & 17 & 14 & 3 & 5 & 2 & 3 & Partial & Partial & Partial \\
\hline Achieving & 3 & 4 & 1 & 0 & 0 & 0 & Perfect & Partial & Partial \\
\hline Mastery & 0 & 0 & 0 & 0 & 0 & 0 & Perfect & Perfect & Perfect \\
\hline
\end{tabular}

Legend: $\boldsymbol{a}$-researcher 1, $\boldsymbol{b}$ - researcher 2, $\boldsymbol{A}$ - expert 1, B-expert 2, Dab-difference between researchers 1 and 2, $\boldsymbol{D A B}$ - difference between expert 1 and 2, $\boldsymbol{R}$ - qualitative description of expert, $\boldsymbol{E}$ - qualitative description of researchers and $\boldsymbol{P} \boldsymbol{A}$ - percentage of agreement. 
It can be interpreted in Table 10 that the respondents are found to be in the developing in terms of cultural reference it indicates that the respondents can communicate in their vernacular language as Tagalog but there was a problem in their use of words and the way they process their answers despite the use of the vernacular language. The results may be attributed that respondents often use Tagalog in their conversation and during class hours. The difficulty of using the spoken English may be credited to the fact that respondents had the inadequacy of vocabulary as revealed by the results of interviews and actual observations of the researcher-interviewers.

The notion of sociolinguistic competence refers to an individual's capability to communicate successfully in terms of both effectiveness and appropriateness. The concept is related to debates about the nature of language which was developed by Hymes as a counter concept to Chomsky's proposal of linguistic competence. In contrast to this theoretical position, the concept of communicative competence sees language primarily as a means of communication, intertwined with other communicative media, coupled with and based upon other cognitive and social abilities, related to performance, and comprising all aspects of language including illocutionary and sociolinguistic knowledge, in contrast to being confined to grammar.

The notion has also been developed within second-language teaching and interpersonal communication research. Depending on the specific focus of research, several constitutive components have been identified. It is a gradual concept, with communicative competence underlying performance and being built up with practice and experience. At the same time it may, depending on the communicative purpose, also be a function of more basic traits, states, and abilities (such as social relaxation, mind-reading abilities, and relevant kinds of knowledge). There is a vast amount of research on different aspects of communicative competence, including its implications for personal life; its components and measurement depending on setting and specific communicative function; the development of communicative competence, methods of improvement, and the processes involved in competent communicative behaviors.

Table 11. Percentage of Agreement between the Researchers as to Metaphorical Language

\begin{tabular}{cccc}
\hline Question & \multicolumn{2}{c}{ Researchers } & Difference \\
\cline { 2 - 3 } & $\mathbf{A}$ & $\mathbf{B}$ & \\
2 & 1 & 1 & 0 \\
3 & 0 & 1 & 1 \\
4 & 0 & 0 & 0 \\
Number of Zero's & 0 & 0 & 0 \\
Number of Items & & & 3 \\
Percentage of Agreement & & & 4 \\
\hline
\end{tabular}

Legend-a-researcher 1, b-researcher 2

As analyzed in Table 11, the researchers got 25 percent of agreement in the questions for metaphorical language because the respondents answered the second to fourth questions without using metaphorical language although the questions can determine their work experience, work assignment and the type of establishment they are working. The researchers agreed in the first question because most of the respondents' answers had shown their ability to use figure of speech.

Table 12. Percentage of Agreement between the Experts as to Metaphorical Language

\begin{tabular}{cccc}
\hline Question & \multicolumn{2}{c}{ Experts } & Difference \\
\cline { 2 - 3 } & $\mathbf{A}$ & $\mathbf{B}$ & \\
1 & 1 & 1 & 0 \\
2 & 0 & 0 & 0 \\
3 & 0 & 0 & 0 \\
4 & 0 & 0 & 0 \\
Number of Zero's & & & 4 \\
Number of Items & & 4 \\
Percentage of Agreement & & $100 \%$ \\
\hline
\end{tabular}

Legend- A-expert 1, B-expert 2 
Good communication is needed in every workplace in hospitality industry that makes the On the Job Trainees needs to have it. According to Ingram, (2009) Communication skills are an essential component of a productive workplace, allowing employees to work together cohesively and professionally. Small business owners can do well to hire employees with solid communication skills, and there are also ways to improve communications skills in the workplace to boost employee productivity.

The expert got 100 percent of agreement in the questions for metaphorical language they agreed that question number 1 is reliable because it is found that the respondents answered the questions with metaphor they compared their work to certain things that best described it. They found that the question number 2, 3 and 4 were not reliable based on the respondents answered it without using metaphorical language.

According to Flores (2016) sociolinguistic competence involves a transaction: a person wants to talk to someone because one needs something. He articulated that people routinely engage in communication, which is not an easy activity. He further explained that sociolinguistic competence is an intricate process that requires better understanding of ideas, thoughts, information and metaphorical language. He said that people should learn about the elements of communication-beyond speaker, message, and listener. Learning the knowledge of the elements will also give speakers a clearer understanding of the communication process and its dimensions.

Table 13. Summary of Agreement between the Researchers and the Experts as to Metaphorical Language

\begin{tabular}{|c|c|c|c|c|c|c|c|c|c|}
\hline \multirow[t]{2}{*}{ Criteria } & \multicolumn{2}{|c|}{ Researchers } & \multirow[t]{2}{*}{ Dab } & \multicolumn{2}{|c|}{ Experts } & \multirow[t]{2}{*}{ DAB } & \multicolumn{3}{|c|}{ Qualitative Description } \\
\hline & $\mathbf{A}$ & b & & $\mathbf{A}$ & B & & $\mathbf{E}$ & $\mathbf{R}$ & PA \\
\hline Beginning & 18 & 16 & 2 & 19 & 21 & 2 & Partial & Partial & Partial \\
\hline Developing & 5 & 8 & 3 & 6 & 4 & 2 & Partial & Partial & Partial \\
\hline Achieving & 2 & 1 & 1 & 0 & 0 & 0 & Perfect & Partial & Partial \\
\hline Mastery & 0 & 0 & 0 & 0 & 0 & 0 & Perfect & Perfect & Perfect \\
\hline
\end{tabular}

Legend: a-researcher 1, $\boldsymbol{b}$-researcher 2, A-expert 1, B-expert 2, Dab-difference between researchers 1 and 2, $\boldsymbol{D A B}$ - difference between expert 1 and $2, \boldsymbol{R}$ - qualitative description of expert, $\boldsymbol{E}$ - qualitative description of researchers and $\boldsymbol{P} \boldsymbol{A}$ - percentage of agreement.

It can be interpreted in table that the respondents were found to be in the beginning in terms of metaphorical language as evident in poor English-speaking practices. The respondents could hardly express their ideas in English, as indicated to poor level of English use and structure, as well as too much dependent on Filipino as their vernacular language. The results imply that the respondents had an inadequate knowledge of the metaphorical language and their meanings. These results may suggest that that most of non-education graduates who taught major courses were often observed to using Filipino as a medium of instruction in the classroom. This may also be attributed to the culture of communication adapted in the department.

The results got support from the study of Sapungan et al. (2016) conducted among the Arab students in the Middle East stating that students had poor level of competence in the use of metaphorical language. The study revealed that use of vernacular was attributed to the poor level regardless of students' sex, age, and enrolled program.

In additional, Kraft (2015) said that poor communication skills can send the wrong message even with the right information. Time and energy are wasted when employees don't know exactly what's expected of them. Coaching sessions, formal classroom training and workshops can prevent misunderstandings by helping managers and their employees listen more effectively, ask better questions and provide clear responses. Communication skills training at work fosters more effective interaction among employees and with clients, which, in turn, enables employees to produce higher quality work with greater efficiency.

Table 14. Work Identity Construction

\begin{tabular}{llll}
\hline Res & Symbol & Word Association & Theme \\
\hline 2 & Clock & Work schedule & \\
3 & Book & Learning & \\
6 & Oven & Baking & Tools \\
7 & Clock & Work load & \\
8 & Machine & Working fast & \\
10 & Broom & Cleanliness & \\
\hline
\end{tabular}




\begin{tabular}{llll}
\hline 11 & Clock & Work schedule & \\
12 & Things I don't like & Not passionate & \\
1 & Life & Daily task & \\
5 & Time & Continuous & \\
9 & Life & Daily needs & \\
13 & daily life & Necessity & Abstract Things \\
14 & Future & Greener pasture & \\
17 & Reality & Life & \\
19 & Love & Risk taking & \\
22 & Love & Loyalty & \\
24 & Weather & Unpredictable & \\
25 & Future & Greener pasture & \\
4 & Study & Learning & \\
15 & Study & Knowledge & \\
18 & Study & Skills & Animal \\
20 & Study & Wisdom & Entertainment \\
23 & Studying & Continuous learning & \\
16 & Cow & Hard working & \\
21 & Game & Focus & \\
\hline
\end{tabular}

Table 14 presents the work identity construction obtained from the responses of participants on metaphorical language during the series of interviews conducting among twenty-five (25) participants. The table includes the Respondents, Symbol, Word Association and Theme.

The respondents' responses were based on the interview question, "If there is one thing you can compare your work, what is it?" From the answers of the participants, the researchers extracted the symbols that used to compare their work. Responses varied as the respondents were assigned in different work areas from where they had acquired their distinctive experiences.

The researchers clustered the symbols according to the theme and association of the words. Some respondents used tools like clock, broom, machine, etc. while the others used abstract things such as life, love, reality, etc.; education and learning, animals and entertainment.

As the researchers used the percentage of agreement with the experts, the hotelier and restaurateur interns were found to be in beginning level in sociolinguistic competence. This is manifested in their answers to the questions. Most of them could not construct their words well and having trouble in processing it. Majority of the respondents answered the questions using their Filipino vernacular language but mistakes were still evident especially when the respondents were switching codes form English to Filipino. Though it is acceptable to switch codes when the words, but words have to be connected to each other and the meaning is understood. The hotelier and restaurateur interns can use metaphorical language as they were able to compare their work to inanimate objects; however, mistakes on the structures were evident and grammatical flaws manifested as they processed the language during the interviews.

\section{Conclusions}

Based on the findings the following conclusions appeared to be necessary. The sociolinguistic competence of hotelier and restaurateur interns were found to be in the beginning level relative to register and dialect, cultural reference, and metaphorical language as manifested in their interaction and negotiation of their ideas found in the recordings. Thus, the assumption, that hotelier and restaurateur interns have a good facility and command of the language, and have sociolinguistic competence, was not met.

\section{Recommendations}

In light of foregoing findings and conclusions, the following recommendations are stated. The college may include program in the curriculum for OJT interns for effective communication skills that enable them to improve their constructions of words while communicating with guests. Since majority of the respondents worked as housekeepers who were assigned at the back of the house and worked in the hotel establishment, and they do not usually interact with the guests and customers, hence, their sociolinguistic competence needs to be developed. The college may adapt a program focusing on systemic decision-making processes in the way of communication to enhance the ability of trainees to process their words when interacting with different guests. The interns should 
engage in collaborative learning activities that will develop their understanding of cultural reference in communication and improve their intercultural communicative competence; thus, making them effective crosscultural communicators needed in the international arena. The interns have to learn comparative identification as an effective way of communication that enhances their ability as hoteliers and restaurateurs while using metaphorical language in communicating with their customers and guests. The future researchers may conduct further studies using other variables (discourse, strategic, or linguistic) that can help the students to improve their communicative competence.

\section{References}

Aceron, R. M. (2015a). Conversational Analysis: The Judge and Lawyers' Courtroom Interactions. Asia Pacific Journal of Multidisciplinary Research, 3(5), 120-127.

Aceron, R. M. (2015b). Frequency of Selected Linguistic Features Used in Certain Parts of Teacher Education

Students' Theses. Asia Pacific Journal of Multidisciplinary Research, 3(5), 83-89.

Aceron, R. M. (2015c). Freshman Students' Attitudes and Behavior Towards Advanced Grammar and Composition Teaching. Asia Pacific Journal of Multidisciplinary Research, 3(4), 85-92.

Benjamin. (2013). Dialect and Register. Retrieved from https://forum.wordreference.com/threads/dialect-register/

Canale, M., \& Swain, M. (1980). Theoretical Bases of Communicative Approaches to Second Language Teaching and Testing. Applied Linguistics, I(1). https://doi.org/10.1093/applin/I.1.1

Chin, B. A. (2000), The Role of Grammar in Improving Students Writing.

Creswell, J. (1998). Qualitative Inquiry and Research Design. Choosing Among Five Traditions. London, New Delhi, Thousand Oaks, Sage Publications, 372 p. + notes, index.

Dawson, M., Madera, J., \& Neal, J. (2011). Managing Bilingual Employees: Communication Strategies for Hospitality Manager, C. N. Hilton College, University of Houston, Houston Texas USA.

Educause. (2018). 7 Things You Should Know About Natural Language Processing.

Fettermann, D. M. (1989). Ethnography: Step by step. Newbury Park, CA: Sage Publications.

Flores, R. (2016). Oral Communication in Context. Rex Book Store, Inc.

Hodson, J., \& Macmillan, P. (2014). Dialect in Film and Literature. https://doi.org/10.1007/978-1-137-39394-4

Jaggers J., Mistry K., Lodge A., Alton M., Mericle J., Frush K., \& Meliones J. (2008). Using Six Sigma Methodology to Improve Handoff Communication in High Risk Patients. Advances in Patient Safety: New Directions and Alternative. Approaches, 3. Performance and Tools. AHRQ Publication No. 08-0034-3. Rockville, MD: Agency for Healthcare Research and Quality.

Kraft, D. (2015). On-the-Job-Communication Skills Training for Adults. Retrieved from https://work.chron.com/

Ingram, D. (2009). How to Improve Communication Skills in the Workplace. Retrieved from https://smallbusiness.chron.com/

McWhorter. (2016). What's a Language, Anyway? The Atlantic. Retrieved from https://www.thoughtco.com/dialect-language-term/

Menabney, D. (2018). How to be a Success at Everything, Fast Company.

Tawadorus, M. I., Antiado, D. F., \& Castillo, F. G. (2012). Procedia-Social Behavioral Sciences English Language Oral Communication Needs at the Workplace: Feedback from Human Resource Development (HRD) Trainees. Retrieved from https://www.sciencedirect.com/

Risager. (2006). What is the relationship between language and culture? Retrieved from http://termcoord.eu/2017/03/what-is-the-relationship-between-language- and-culture/

Sapungan, et al. (2016). Level of Competence on the use of Metaphorical Language among the Ffs- Gulf College Students. International Journal on Studies in English Language and Literature (IJSELL), 4(5), May 2016, PP 1-7 ISSN 2347-3126 (Print) \& ISSN 2347-3134.

Singh, D., \& Ad, A. (2017). Motives of Selecting Housekeeping Department as Career-A Study of Selected Hotel in North India

Spitzberg, B. H. (2018). A Model of Intercultural Communication Competence.

Traxler, M., \& Gernsbacher, M. (2018). Handbook of Psycholinguistic, second edition. 
Wiley-Blackwell, Fernandez, E., \& Cairns, H. (2011). Fundamentals of Psycholinguistics. Retrieved from https://books.google.com.ph

Weiss, R. (1994). Learning From Strangers; The Art and Method of Qualitative Interview Studies. New York, The Free Press, 222 p. + notes, index.

Young, J. (2012). How Did That Register? Five Levels of Formality in Language. Retrieved from https://www.altalang.com/

\section{Copyrights}

Copyright for this article is retained by the author(s), with first publication rights granted to the journal.

This is an open-access article distributed under the terms and conditions of the Creative Commons Attribution license (http://creativecommons.org/licenses/by/4.0/). 